\title{
CORRESPONDENCE
}

\section{The Johns Hopkins and India}

SIR - In the news section of your 11 March issue, K. S. Jayaraman from New Delhi makes several serious and erroneous allegations regarding the Johns Hopkins University and its participation in research projects in India. I believe it to be important that the record be corrected.

For many years, scientists from the Johns Hopkins University collaborated with Indian colleges in two major projects. One was the pioneering research conducted from 1961 to 1974 at the Narangwal Rural Health Research Centre in the Punjab. The purpose was to design and evaluate practical approaches for the delivery of primary health care. A series of projects under the Indian Council of Medical Research involved a large group of Indian scientists and a few foreign scientists under the direction of Professor Carl Taylor. These studies served as a prototype for other similar health services research subsequently conducted in many countries throughout the world. Professor Taylor, a member of the Institute of Medicine of the National Academy of Sciences and a frequent consultant to the World Health Organization, the World Bank and many other national and international organizations, is universally recognized as an authority in the complex problems of primary health care delivery. He was born in India and has spent half of his life living and working in the villages of the subcontinent. Contrary to Mr Jayaraman's report, the Indian government has officially confirmed that he has never been expelled from India nor has he been forbidden to come to India or any other country in a professional capacity. His visits to India since the Narangwal Project closed have been in response to official invitations. The allegation that the purpose of the Narangwal study was to provide a base for spying on the Halwara airbase is wholly false, indeed preposterous.

The second project, based at several national institutes in Calcutta, was under the direction of the late Professor Frederik Bang. It was one of a group of International Centers for Medical Research and Training which were funded by the National Institutes of Health. With Indian scientific colleagues, a large number of important investigations were conducted dealing with infectious diseases and nutrition. Indeed, many of the fundamental studies which have led to the now universally used methods for treatment of cholera and other severe diarrhoeas with oral fluid therapy were made by the Calcutta group. This laboratory and its scientific staff had no connection whatsoever with the Fort Detrick biological warfare laboratory. There was also no link with the US Navy except for informal, collegial scientific exchanges with the Naval Medical Research Unit, then based in Taipei, which was similarly actively engaged in endeavouring to find more effective and practical methods for the treatment of cholera.

Since its founding in 1916, the Johns Hopkins School of Hygiene and Public Health has been deeply involved in education and research in international health problems in Baltimore and in many countries throughout the world. It continues today as one of the largest institutions so concerned with international health. Its numerous alumni hold eminent positions in national and international organizations around the world. The false aspersions cast on the the institution by $\mathrm{Mr}$ Jayaraman are deeply resented.

\section{A. Henderson}

(Dean)

The Johns Hopkins University, School of Hygiene and Public Health, Baltimore, Maryland, USA

\section{Ban the billion}

SIR - A.J. Southward (Nature 294, 215; 1981) writes: ". . estimated six billion tons of oil that reaches the sea each year"'. as he comes from Plymouth, Devon, we have a right to expect that "billion" means $10^{12}$ : but in context that is surely impossible. We are therefore left to wonder whether he writes in American from an English address.

Unfortunately, even " $6 \times 10^{9}$ tons" of oil per year flowing into the sea sounds fantastic, given that the world's production of crude oil is about $3 \times 10^{9}$ tons per year. Does that mean that most of the amount talked about is natural seepage? The rest of the article makes that sound implausible. We are left with the uncomfortable feeling that, as the author has introduced one uncertainty of a factor of 1,000 , he may just have got the figure wrong.

The confusion is worse confounded by the difficulty of distinguishing spoken " $m$ " and " $b$ ", especially on the telephone. As a result, "million" and "billion" are frequently confused, particularly in newspapers. The uncertainty is thus increased to $10^{6}$.

Sir, could I prevail upon you simply to ban the word "billion" from Nature? It seems to me unnecessary; given the enormous uncertainty, it would be much better simply replaced by " 109 " or "thousand million". EDWARD EISNER

Department of Applied Physics,

University of Strathclyde,

Glasgow, UK

\section{A. J. SOUTHWARD REPLIES - Mea culpe:} Professor Eisner is quite entitled to his little bit of fun. The word should have been million -6 million tons of oil per annum into the sea. 1 agree that the word billion needs replacing.

\section{PhD applications}

SIR - The leading article in Nature of 15 April (p.592) implies that "promising people from less favoured universities" find it hard to enter PhD courses because the quota system of awards puts graduate student selection into the hands of the luckier university departments.

I expect that supervisors usually want to choose the most productive and biddable graduate students quite independently of their college of origin. If this is so, the main barrier to students moving to a new institution for their graduate studies must be inadequacy of information about projects and places available elsewhere.

For several years this department (which has always had a strict policy of not allowing its own honours students to continue as $\mathrm{PhD}$ students here), has organized a scheme for exchanging this information amongst about 80 UK life science departments - mainly in biochemistry, molecular biology, microbiology and cell biology. The scheme also promotes a common application form and loosely coordinated timetable for selection.

This year, for the first time, we have published the Compendium of Research Topic Outlines, which forms part of the scheme, as a single volume of over 400 pages, with name and subject indexes. The first indications are that this has proved very useful to students in finding out where they can carry out the kind of research of most interest to them. In the future, the availability of this compendium to libraries and career advisers should make the system of greater use to students in nonparticipating departments.

I shall be glad to answer enquiries from anyone who thinks that the compendium, or the scheme as a whole, could be useful to their students.

I think that many of the participating departments now find the scheme indispensable, as we do. For this reason I have never understood why physical chemical and social science departments do not cooperate in a similar way.

A. F. W. COULSON

Department of Molecular Biology,

University of Edinburgh,

Edinburgh, UK

\section{Man mismeasured}

SIR - Scientifically I am certainly no supporter of the main thesis of Stephen Jay Gould concerning punctuated equilibrium. Thus I might be expected to be in favour of (or at least to watch passively) virtually anything that helps to reduce Gould's immense influence and effectiveness, especially if prepared by an outsider to the evolutionary arguments. But in truth, I found the personal attack on Gould by your reviewer of The Mismeasure of Man (Nature 8 April, p.506) positively nasty, unprofessional, with but slight reference to substantive issues (and then often granting Gould's correctness), and just plain ugly. Who is Mr Blinkhorn to tell us that the book has "the routine flavour of Radio Moscow news broadcasts", as though in and of itself even if it were true (which is not in any way documented), it should damn the book for ever. My reaction is that if Blinkhorn is correct, more of us should join him in listening to those radio waves. Blinkhorn ends by admiring Gould's skill in presentation, and adding "but what a waste of talent". For his part, Blinkhorn has shown us a remarkable lack of skill, unfortunately presumably making full use of his talent.

ThOMAS J.M. SCHOPF Department of Geophysical Sciences, University of Chicago, Chicago, Illinois, USA 